\title{
Conhecimento de enfermeiros da atenção básica na detecção precoce da síndrome HELLP
}

\section{Knowledge of primary care nurses in the early detection of HELLP syndrome}

Pablo Luiz Santos Couto, Mirian Santos Paiva, Viviane Melo Chaves, Alba Benemérita Alves Vilela, Núbia Rêgo Santos, Samantha Souza da Costa Pereira, Isnara Francis Rodrigues Santos Antunes, Luana Costa Ferreira, Magno Conceição das Merces

Como citar este artigo: COUTO, PABLO L. S.:

PAIVA, MIRIAN S.; CHAVES, VIVIANE M.; VILELA, ALBA B. A.; SANTOS, NÚBIA R.; PEREIRA, SAMANTHA S. C.; ANTUNES, ISNARA F. R. S.; FERREIRA, LUANA C.; MERCES, MAGNO C.; Conhecimento de enfermeiros da atenção básica na detecção precoce da síndrome HELLP. Revista Saúde (Sta. Maria). 2020; 46 (1).

\section{Autor correspondente:}

Nome: Pablo Luiz Santos Couto E-mail: pablolvizsc@hotmail.com Formação Profissional: Enfermeiro, Mestre em Enfermagem, Centro de Ensino Superior de Guanambi. Guanambi (BA), Brasil

Filiação Institucional: Centro de Ensino Superior de Guanambi Endereço para correspondência: Av. Pedro Felipe Duarte Bairro: São Sebastião

Cidade: Guanambi

Estado: Bahia

CEP: 46430-000

Data de Submissão:

01/08/2019

Data de aceite:

30/03/2020

Conflito de Interesse: Não há conflito de interesse

\section{(cc) $\mathrm{BY}-\mathrm{NC}-\mathrm{ND}$}

\section{RESUMO}

Objetivo: analisar o conhecimento de enfermeiros da atenção básica na detecção da Síndrome HELLP. Método: estudo qualitativo, realizado em um município do Nordeste Brasileiro com 18 enfermeiros coordenadores das unidades Estratégias de Saúde da Família que compõem a Atenção Básica do município. Foi realizada uma entrevista em profundidade com o auxílio de um roteiro com três questões abertas. As falas foram analisadas mediante a Análise de Conteúdo Semântica. Resultados: evidenciou-se duas categorias que retratam uma realidade preocupante quanto às desinformações dos enfermeiros sobre a síndrome e a consequente falta de conhecimento, decorrente do pouco contanto com gestantes que manifestam as complicações dessa toxologia gravídica ou até mesmo pela dificuldade em identificá-la e detectá-la precocemente, condutas preventivas ineficazes, e também falha na referência e contra referência. Conclusão: conclui-se que os enfermeiros da atenção básica apresentam falhas no cuidado, por apresentarem dificuldades na detecção precoce, que são reflexo do desconhecimento acerca deste agravo, o que evidencia a necessidade em promover educação continuada com os profissionais.

PALAVRAS-CHAVE: Síndrome HELLP; Gravidez de Alto Risco; Enfermagem; Atenção Primária à Saúde; Hipertensão Induzida pela Gravidez.

\section{ABSTRACT}

Objective: to analyze the knowledge of primary care nurses in the detection of HELLP Syndrome. Method: a qualitative study, conducted in a municipality in the Northeast of Brazil with 18 nurses who coordinated the Family Health Strategies units that make up the city's Primary Care. An indepth interview was conducted with the help of a script with three open questions. The speeches were analyzed using the Semantic Content Analysis. Results: there were two categories that portray a worrying reality regarding the nurses' lack of information about the syndrome and the consequent lack of knowledge, due to the little contact with pregnant women who manifest the complications of this pregnancy toxology or even the difficulty in identifying it and detect it early, preventive conduct ineffective, and also failure in referral and against referral. Conclusion: it is concluded that primary care nurses have flaws in care, as they have difficulties in early detection, which are a reflection of the lack of knowledge about this condition, which highlights the need to promote continuing education with professionals.

KEYWORDS: HELLP syndrome; High Risk Pregnancy; Nursing; Primary Health Care; PregnancyInduced Hypertension. 


\section{INTRODUÇÃO}

As Síndromes Hipertensivas da Gestação (SHG) conhecida também como toxemia gravídica é uma enfermidade obstétrica que surge após a vigésima semana de gestação, com maior frequência de complicações severas no terceiro trimestre, podendo-se estender até o puerpério. Apresenta características como hipertensão arterial, edema e/ou proteinúria, podendo ocasionar convulsões e coma. Quando não tratada evolui naturalmente para as formas graves, entre elas, a eclampsia e a Síndrome HELLP $(\mathrm{SH})^{1}$.

A Síndrome HELLP se caracteriza por hemólise $(H)$, enzimas hepáticas elevadas $(E L)$ e baixas contagem de plaquetas (LP), sendo que a sua abreviação é construída através de suas características. Mesmo conduzindo diversas complicações obstétricas como o descolamento placentário precoce, coagulação intravascular disseminada (CIVD), insuficiência renal aguda, hematoma hepático subcapsular, descolamento de retina, a paciente pode evoluir insuficiência renal, cardíaca e pulmonar, crescimento uterino limitado e síndrome da angústia respiratória no feto, cuja causa ainda não foi identificada ${ }^{2-3}$.

Embora seja menos frequente que a pré-eclâmpsia, o óbito materno decorrente Síndrome HELLP varia de 1,1\% em países desenvolvidos a $24 \%$ em países subdesenvolvidos. A intensidade desse agravo, em média, pode acontecer em 24 a 48 horas após o parto; 31\% podem ocorrer no pós-parto e, destas, 20\% sem apresentar pré-eclâmpsia prévia, agravando ainda mais o quadro. A Síndrome tem alta morbimortalidade; caracteriza-se como uma condição rara, que traz risco de morte, e que ocorre entre $0,2 \%$ a $0,6 \%$ das gestações. Algumas gestantes desenvolvem apenas uma ou duas das características da Síndrome ${ }^{4}$.

As pacientes com pré-eclâmpsia grave $0,5 \%$ a $0,9 \%$ de todas as grávidas estão propensas à mortalidade e morbidade significativas, o que aumenta de acordo com a gravidade da Síndrome HELLP. As taxas de morbidade e mortalidade entre as mulheres grávidas com Síndrome HELLP são perinatal/infantil. Cerca de $70 \%$ das gestantes que apresentam a síndrome, $15 \%$ dos casos necessitam de parto prematuro antes da $27^{a}$ semana da gestação ${ }^{4-5}$.

Devido às alterações hepáticas, a síndrome era frequentemente confundida com quadro de hepatite ou então de colecistite, até ser reconhecido como uma doença específica, o seu tratamento era retardado desfavorecendo tanto a saúde do feto quanto da mãe. A Síndrome HELLP é instituída como um item a parte das demais síndromes hipertensivas, contudo pode ser um agravamento da SHG ou mesmo aplicada à condição clínica da hipertensão arterial crônica ${ }^{6}$.

O diagnóstico final da Síndrome HELLP em sua maioria é realizado de forma tardia, uma vez que a sintomatologia do quadro clínico pode ser associada a outras enfermidades. Os sintomas constituintes dessa patologia podem fazer parte de síndromes virais, distúrbios muscular-esqueléticos, úlceras pépticas, hepatite aguda, doença da vesícula biliar, 
pielonefrite, pancreatite, anemia hemolítica microangiopática. Algumas pacientes podem não apresentar estes sintomas de diagnóstico, logo são consideradas portadoras da síndrome de forma parcial, o que não a impede de uma progressão para a expressão extrema da patologia em $\mathrm{si}^{2}$.

O profissional em enfermagem, especificamente o enfermeiro na atenção básica, ao acompanhar a gestação, deve atentar-se no que se refere aos fatores de risco, às manifestações clínicas iniciais e às diversas complicações, e também ao fator emocional da gestante, dando as devidas orientações e esclarecimento das dúvidas sobre as patologias e seus possíveis agravos. Este é um fator indispensável a ser trabalhado, por haver déficit de conhecimento da gestante acerca dos cuidados a serem tomados durante este período e das medidas de prevenção das complicações?

Desse modo, é importante que sejam realizadas intervenções com gestantes, que apresentam o quadro clínico de hipertensão, pois assim o profissional de enfermagem terá o papel de regularizar este quadro minimizando os agravos e problemas. Desta forma, atuará com o intuito prevenir complicações de agravos e controlar a situação da gestante como o controle de eletrólitos, infecção, ansiedade, aferição dos níveis pressóricos, avaliação da proteinúria e repouso ${ }^{7}$.

Desta forma, em decorrência da alta incidência das patologias hipertensivas, as ações voltadas para o diagnóstico e tratamento devem ser mais valorizadas pelos profissionais de saúde por meio da utilização de conhecimentos técnicocientíficos, recursos adequados e disponíveis para cada caso.

A Síndrome HELLP exige um maior aprofundamento sobre as manifestações clínicas que a gestante possa apresentar durante a gravidez, pois a síndrome requer extrema atenção exigindo do profissional enfermeiro, em casos de desordens e agravos obstétricas, que o mesmo possa precocemente identificar e minimizar situações de risco de óbitos, tanto materno quanto fetal, para que se haja maior resolutividade no cuidado e melhoria na qualidade da assistência ${ }^{3}$.

Assim, esse estudo justificou-se pela necessidade de ampliar o conhecimento sobre o que as enfermeiras da atenção básica entendem da Síndrome HELLP, bem como se os enfermeiros possuem a compreensão da evolução da síndrome e do diagnóstico dos sinais e sintomas, para que possam atuar na detecção dos fatores de risco e a detecção precoce do agravo. Além disso, há o intuito de favorecer a ampliação dos conhecimentos dos profissionais de enfermagem sobre a SH, para que sejam desenvolvidos futuramente protocolos que auxiliem esses profissionais na atenção básica à saúde.

Diante disso, questiona-se, qual o nível do conhecimento de enfermeiros da atenção básica que tem contato com as gestantes nas consultas pré-natal quanto à identificação dos fatores de risco e da detecção precoce da Síndrome HELLP? Para auxiliar na elucidação deste questionamento, objetivou-se, analisar o conhecimento dos enfermeiros da atenção básica na detecção precoce da Síndrome HELLP. 


\section{MÉTODO}

Trata-se de um estudo de caso do tipo descritivo, com a abordagem qualitativa. $\mathrm{O}$ estudo de caso é uma investigação empírica, focal e situacional de um fenômeno contemporâneo dentro de seu contexto da vida real, cujos limites algumas vezes não estão definidos ${ }^{8}$. Já a abordagem qualitativa, não se atenta com representatividade numérica, todavia, irá aprofundar na compreensão de um grupo social, etc. Esse tipo de pesquisa trabalha com o universo de significados, motivos, aspirações, crenças, valores e atitudes, o que corresponde a um espaço mais profundo das relações, dos processos e dos fenômenos que não podem ser reduzidos à operacionalização de variáveis ${ }^{9-10}$.

A coleta de dados ocorreu em abril de 2017 e foi realizada nas Unidade Básicas de Estratégias Saúde da Família (ESF) do município de Guanambi-BA, com por enfermeiros que atuam na atenção básica, os quais compuseram os participantes do estudo. Ao todo são 20 enfermeiros que atuam e coordenam as ESF's, entretanto participaram 18, uma vez que 02 recusaram participar. Não houve a necessidade dos critérios de exclusão.

A técnica de pesquisa adotada para este estudo foi à entrevista em profundidade, que se adéqua a uma pesquisa qualitativa. A entrevista em profundidade é um processo social ou que há uma interação em que o meio de troca seja as palavras, a mesma passa a ser considerada; pode-se então perceber que é mais uma interação com troca de ideias e significados, desenvolvendo-se e explorando as percepções e realidades, ou seja, não é uma abordagem em que uma pessoa responde e a outra que perguntou ouvirá apenas ${ }^{11}$.

Adotou-se como instrumento de pesquisa, um roteiro para entrevista em profundidade que serviu para coletar as falas/respostas dos participantes. 0 roteiro foi composto de (questões para caracterização das/dos participantes) e três questões abertas: "fale-me o que você entende por síndromes hipertensivas"; fale-me o que você sabe sobre a síndrome hellp"; "fale-me quais as suas condutas para a detecção precoce da síndrome hellp e dos fatores de risco". As entrevistas tiveram média de duração de 30 minutos, cujas respostas foram gravadas com o recurso de gravador de voz dos aparelhos celulares. Logo em seguida, as respostas foram transcritas (digitadas) na íntegra no Microsoft Word 2016.

A análise das falas foi realizada por meio da análise de conteúdo semântica, a qual permite reconstruir 'mapas de conhecimento' à medida que eles estão materializados em textos. Para reconstruir esse conhecimento foi realizada a préanálise e leitura exploratória do material, classificação das unidades do texto, reorganização das unidades decodificadas, interpretação para a apreensão das semelhanças e divergências semânticas, agrupamento das semelhanças e desdobramentos das categorias ${ }^{12}$.

A pesquisa obedeceu aos princípios éticos da Resolução n 466/2012 e foi submetida à Plataforma Brasil e aprovada pelo Comitê de Ética em Pesquisa sob número de protocolo 2023020/2017, possuindo como princípios, sigilo e respeito ao participante da pesquisa em sua dignidade e autonomia, permitindo sua vontade de contribuir e permanecer, ou não, na pesquisa, por intermédio de um pronunciamento e mediante a assinatura do Termo de Consentimento Livre e Esclarecido. 


\section{RESULTADO E DISCUSSÃO}

Os participantes da pesquisa em sua maioria (18) são do sexo feminino e dois (02) participantes do sexo masculino, com idade entre 26 a 47 anos, maioria com estado civil casado (15). Em relação à complementação da formação, as participantes têm especialização em saúde da família (10), saúde pública (6) e urgência e emergência (2). Em relação ao tempo de formação, há uma variação entre 2 a 10 anos.

Após a realização das entrevistas, os dados coletados foram analisados e interpretados baseando-se na convergência semântica das respostas e dos sentidos que os enfermeiros deram sobre os aspectos pesquisados. Para melhor compreensão do conhecimento e percepção dos profissionais emergiram duas categorias: Categoria I: Uma síndrome pouco conhecida entre os profissionais da atenção básica. Categoria II: Falhas na detecção precoce, o que torna a conduta ineficaz.

\section{Uma síndrome pouco conhecida entre os profissionais da atenção básica.}

Os enfermeiros da atenção básica foram questionados sobre a percepção da Síndrome HELLP, dentre alguns relatos obtidos, pode-se perceber que os profissionais têm conhecimento defasado sobre a síndrome.

"nunca ouvi falar da síndrome Hellp, mas vou está pesquisando, mas a nossa conduta é a mesma em relação ao aumento da pressão". (ENFERMEIRA 2)

"a Síndrome HELLP, eu nunca tive aqui no posto, e não sei falar muito sobre ela, e eu acho que ela é um pouco mais complicada". (ENFERMEIRA 3)

"pode ser que já teve e a gente não detectou mas sempre orientamos sobre o aumento da pressão, não sei muito sobre essa síndrome não". (ENFERMEIRA 6)

"eu nunca tinha ouvido falar não a respeito". (ENFERMEIRA 8)

O desconhecimento sobre a Síndrome HELLP por parte dos enfermeiros da atenção básica traz consigo falhas durante o acompanhamento do pré-natal, pois muitas informações podem não ser relatadas ou passam despercebidas pelo profissional, dificultando o diagnóstico precoce da síndrome e aumentando os fatores de ricos para as gestantes.

Considerando os resultados obtidos, o estudo realizado em Teresina - PI no ano de 2012, evidenciou que as condutas de enfermagem são bastante mecanizadas, isto é, os cuidados se resumem apenas, na verificação da pressão 
arterial e na administração de medicamentos, não havendo ênfase nos aspectos psicológicos, comprovando a limitação da assistência de enfermagem prestada a gestante apenas, aos procedimentos técnicos ${ }^{13}$.

A realização e o acompanhamento adequado do pré-natal prevê a captação da gestante, realizando no mínimo, seis consultas. Assim, o objetivo maior do pré-natal será cumprido: a prevenção de morbidades e mortalidade perinatal ${ }^{4}$. Desse modo, a adequação dos registros ficará evidente a evolução do paciente e de seu tratamento. Isso se faz fundamental para o diagnóstico precoce e o tratamento adequado tanto materno quanto perinatal ${ }^{14}$. A falta de conhecimento dos enfermeiros pode implicar em riscos maternos e fetais, pois exames e procedimentos terapêuticos podem ser negligenciados ou repetidos sem necessidade.

Assim, quando a Síndrome HELLP é detectada precocemente, aumentam as chances de sobrevivência da grávida e do feto terem higidez durante a gestação; este é o principal motivo pelo qual o enfermeiro deve atentar-se a qualquer sintoma de anormalidade durante as consultas de pré-natal. O diagnóstico tardio favorece o surgimento de complicações sérias como insuficiência renal aguda, edema agudo de pulmão, hematoma hepático ou ruptura hepática, podendo levar a óbito. O acompanhamento e vigilância permanente da gestante com variação pressórica significativa é o ideal; até porque as Síndromes Hipertensivas são uma das principais causas de mortalidade materna ${ }^{15}$.

Essa falha na detecção da Síndrome HELLP remete a possível falta de conhecimento do enfermeiro que atua na atenção básica, influenciado por fatores educacionais de base durante a graduação, como falhas no processo de ensino-aprendizagem. Acredita-se na importância do conhecimento mais aprofundado como estratégia para melhorar a qualidade da assistência de enfermagem, pois assim, a autonomia e credibilidade serão alcançadas além da prática da profissão com responsabilidade e comprometimento ${ }^{15-16}$. Esse pode ser o primeiro e importante passo para mudar essa realidade do enfermeiro, que estão na ponta da assistência, na promoção e prevenção à saúde, ou seja, possibilitar qualificação profissional, com atividades de educação permanente focalizada na gestação de alto risco, sobretudo no conhecimento das síndromes gestacionais mais raras e graves ${ }^{16}$.

Nesse contexto, durante as consultas de pré-natal, pouco se investiga acerca do conhecimento que as mulheres têm, quer sobre o processo gestacional, quer sobre suas complicações. Esse resultado é semelhante ao estudo realizado no Rio Grande do Norte no ano de 2014 que sugere que os profissionais pouco discutem com as pacientes durante 0 pré-natal as complicações e o tratamento das síndromes hipertensivas e da pré-eclâmpsia ${ }^{17}$.

É importante que profissionais de saúde, como os enfermeiros, esclareçam as dúvidas e transmitam às gestantes conhecimentos que as despertem para o autocuidado, pois o cuidado educativo é uma das principais ações que devem ser implementadas em saúde. A assistência pré-natal deve ampliar suas ações para além de questões meramente curativas ou biologistas, mas com ações de educação em saúde preventiva capacitando as mulheres para o autocuidado e, consequentemente, para a manutenção de sua saúde ${ }^{15}$. 
Além da assistência prestada pelo Enfermeiro durante o período de pré-natal, parto e puerpério, é fundamental que este profissional tenha a compreensão do processo da síndrome hipertensiva durante a gestação, da relevância dos sinais clínicos, como também é importante o conhecimento da etiologia e fisiopatogênia. Dentre os principais cuidados relacionados à assistência de enfermagem nas síndromes hipertensivas podem-se citar: avaliação rigorosa dos sinais vitais de 2 em 2 horas, avaliação constante do débito urinário, verificação dos reflexos, controle dos batimentos cardiofetal, orientar decúbito lateral esquerdo, atentar-se para cefaleia, distúrbio visual, dor epigástrica e nível de consciência, que podem revelar complicações fisiológicas graves na mulheres ${ }^{18}$.

Salienta-se que há uma provável tendência de aumento e/ou surgimento de casos de gestantes com a síndrome, é imprescindível que os enfermeiros ampliem o conhecimento, para que, sua atuação seja conforme a necessidade ${ }^{19}$. Assim, será possível a realização do diagnóstico precoce, permitindo o levantamento de problemas, facilitando a tomada de decisões e, a busca de melhoria da assistência prestada.

\section{Falhas na detecção precoce, o que torna a conduta ineficaz.}

Nesta categoria foram analisados os relatos em relação à detecção precoce da Síndrome HELLP, sendo que dos 18 enfermeiros que responderam à pesquisa, somente 3 enfermeiras conheciam as manifestações clínicas da síndrome, a maioria apresentou falhas ou incongruências em suas condutas. Conforme alguns relatos seguem citados.

"[...] a partir do pré-natal nós vamos conseguir identificar esses fatores, a partir de exames laboratoriais, anamnese, na anamnese mesmo a gente vai poder identificar na conversa, os sintomas que ela apresentar vai poder falar e o que ela sentir a gente". (ENFERMEIRA 1)

"Então a detecção essa questão está dentro da outra. A detecção através da consulta mesmo que faz com o pré-natal nessa consulta vai ver a P.A, se apresenta edema se tem inchaços nas pernas se tem alguma queixa, cefaleia intensa até vomito, não acontece em todas em algumas, mas tem caso que tem". (ENFERMEIRA 4)

"É seguir o protocolo do pré-natal solicitação dos exames do pré-natal, todos exames laboratoriais mais precoces possíveis realizar exame físico completo dessa paciente ausculta qualificada em todas as consultas de pré-natal oferecendo para ela pré-natal de qualidade dando ênfase na verificação da pressão arterial na presença de edemas na presença desses sintomas que são características das urgências hipertensivas". (ENFERMEIRA 5) 
"eu não tive a oportunidade de ter nenhuma paciente que eu tenha detectado que estava nesse estágio tive e acompanhei paciente com síndrome hipertensiva, mas leve, mesmo por que assim eu gostos muito do serviço do pré-natal do alto risco eles acompanham muito bem essas gestantes". (ENFERMEIRA 7)

"Na verdade, eu acho assim o PSF para você detectar uma síndrome de HELLP é muito precoce, mas assim geralmente no PSF é muito difícil agente esta detectando, mas é mais detectado no pré-natal de alto risco". (ENFERMEIRA 8)

"No caso da Síndrome HELLP a gente sabe que nem sempre a causa seria a pressão alta, existem outras causas que pode levar a Síndrome HELLP como a gente sabe as plaquetas aumentadas leva a Síndrome HELLP, no caso da Síndrome HELLP a gente encaminha para o pré-natal de alto risco". (ENFERMEIRA 12)

"Bom as condutas a princípio é justamente a aferição da PA, é o acompanhamento dessas gestantes as orientações que nós damos para elas nessa primeira consulta, orientação de alimentação de acompanhamento, sentiu dores de cabeça qual o local". (ENFERMEIRA 16)

"aqui o acompanhamento que a gente faz coma gestante são consultas normais, eu a encaminho para o pré-natal de alto risco, no Hospital Regional, que ela vai estar lá acompanhada pelo um obstetra, que paciente assim deve ser assistida com maior cuidado, não que aqui ela não vai ser, mas lá tem uma preparação maior". (ENFERMEIRA 20)

Conforme os relatos percebem-se que as enfermeiras 4, 5 e 12 conhecem a Síndrome HELLP, além de indicarem os procedimentos ideais para a detecção precoce da síndrome. As outras enfermeiras trazem uma abordagem voltada para as Síndromes Hipertensivas da Gestação, ou seja, a abordagem é exclusivamente voltada para o controle da pressão arterial deixando de analisar outros fatores que são específicos para a detecção da Síndrome HELLP, tais como: anemia hemolítica microangiopática (presença de esquizócitos nos esfregaços sanguíneos e LDH> $600 \mathrm{UI} / \mathrm{L}$ ), níveis elevados de transaminase (AST> $70 \mathrm{UI} / \mathrm{L}$ ) e trombocitopenia (Plaquetas $<100.000 \mathrm{~mm} 3)^{20,21}$.

O fato de a Síndrome HELLP ocorrer em cerca de 0,2 a 0,8\%, presume-se que a hipertensão é consistente nestes casos, entretanto, ressalta-se que os sinais de pré-eclâmpsia (PE) podem ser sutis, tendo a necessidade da deteç̧ão precoce e o diagnóstico preciso. Os sintomas maternos podem ser vagos e confundidos facilmente com uma 
variedade de complicações fisiopatológicas ou obstétricas que deve ser excluído. Existem dois diagnósticos principais para a detecção da Síndrome HELLP20.

Essa síndrome também envolve alterações na ativação plaquetária, na elevação dos níveis séricos de ocitocinas que levam ao vaso espasmo, acarretando obstrução sinusoidal e infarto hepático. As áreas de necrose podem sangrar o que leva à formação de hematomas subcapsulares ${ }^{(14)}$. Situações traumáticas como vômitos, transporte da paciente, contrações uterinas efetivas e convulsões podem contribuir para hemorragia hepática. A hemólise microangiopática, com consequente circulação de fragmentos de células vermelhas, leva à lesão íntima vascular, acarretando depósito de fibrina nos sinusóides hepáticos, tendo como consequência uma necrose hemorrágica ${ }^{3,22}$.

Em um estudo de revisão dos prontuários de todas as gestantes diagnosticadas com a Síndrome HELLP na Unidade de Cuidados Intensivos Polivalente (UTI) hospitalar Manuel Ascunce Domenech da Universidade de Camagüey em Cuba realizado por Jiménez Fiz et al. (2014), a síndrome tem uma incidência de 0, 2 a 0, 6\%, e 4 a 12\% em doentes com pré-eclâmpsia. A mortalidade materna associada com a Síndrome HELLP se encontra entre 1 a $25 \%$, e perinatal é de 10 a $60 \%$ (média de 35\%)²2.

Ela está associada a complicações tais como eclâmpsia, disfunção renal, hemorragia intracraniana, hemorragia, complicações do fígado e coagulopatía, incluindo coagulação intravascular disseminada, descolamento, insuficiência renal aguda, e edema pulmonar agudo. Complicações menos comuns (menos de 1\%) são: ascite, derrame pleural, derrame pericárdico e hematoma e/ou hepáticos, ascite e derrame pleural pode contribuir para o desenvolvimento de insuficiência respiratória. A síndrome no pós-parto apresenta uma elevada incidência de disfunção renal e edema pulmonar aguda, sendo muito alta a mortalidade ${ }^{4,22}$.

A Síndrome HELLP caracteriza-se quando em repouso os valores da pressão arterial são maiores ou iguais a 160/110 mmHg, proteinúria grave e oligúria (< $400 \mathrm{~mL} 24$ h-1), alterações visuais, cefaleia e outras alterações cerebrais, dor epigástrica, sinais de edema pulmonar, cianose e Síndrome HELLP. Pacientes com essa síndrome ficam suscetíveis a alta incidência de acidentes vasculares cerebrais, doenças cardíacas rotura placentária necessidade de transfusão de sangue, efusão pleural e infecções. Muitos casos de HELLP ocorrem no pré-termo, mas 20\% podem ocorrer no póstermo, com maior incidência nestes de edema agudo de pulmão23.

Em pesquisa que analisou estudos desenvolvidos entre 1994 a 2019 sobre a pré-eclâmpsia e as síndromes hipertensivas da gestação, verificou-se que dentre as gestantes com pré-eclâmpsia grave $(0,5 \%$ a 0,9\%) estão propensas à mortalidade e morbidade significativas, o que aumenta de acordo com a gravidade evolui para a Síndrome HELLP5. Esta síndrome decorre do aumento do risco materno do desenvolvimento de morbidades, incluindo complicações cerebrovasculares, hemorragia, edema pulmonar, descolamento da retina, hematoma/hepática, insuficiência renal aguda, insuficiência hepática, insuficiência coagulopatia, desprendimento placentário e sepse ${ }^{24}$. 
Dentre as mulheres grávidas com Síndrome HELLP, as taxas de morbidade e mortalidade perinatal/infantil são para o prematuro de cerca de $70 \%$ nos doentes com Síndrome HELLP com cerca de $15 \%$ dos casos necessitam de parto antes da $27^{\mathrm{a}}$ semana da gestação ${ }^{25}$.

São tais informações supracitadas, que tornam-se fundamentais no arcabouço de conhecimento do enfermeiro na atenção básico, visto que ele precisa orientar as gestantes sobre as dúvidas e auxiliar na detecção precoce para a tomada de decisão e implementação de medidas de antecipação, como por exemplo, garantir a referência e contrareferência e articular a rede atenção à saúde da gestante ${ }^{4-5,25}$.

É fundamental também que o enfermeiro conheça, principalmente as manifestações clínicas, que por vezes são inespecíficas e a suspeita clínica é fundamental para o diagnóstico precoce. O quadro clínico se comporta de modo evolutivo, que se inicia com náuseas, vômitos, dispneia, dor epigástrica, em quadrante superior do lado direito do abdome, com irradiação para a escápula, acompanhada de hepatomegalia dolorosa à palpação. Após a ruptura do hematoma, a dor se exacerba brutalmente e a paciente começa a apresentar sinais e sintomas de colapso cardiovascular, como faces de angústia, pulso rápido e fino, oligúria, hipotensão4 .

Os cuidados de enfermagem, na perspectiva das consultas do enfermeiros durante o pré-natal na atenção básica, prestados à gestante com pré-eclâmpsia, incluem garantir o atendimento de referência e contrarreferência (com atendimento constante no pré-natal de alto rico), além das condutas dele como a aferição dos níveis pressóricos quatro vezes ao dia, preferencialmente em decúbito lateral esquerdo, repouso no leito nesta mesma posição, medição diária de peso, avaliação cotidiana da proteinúria, controle da diurese nas 24 horas, orientações para verificação materna diária dos movimentos fetais e observação pelos profissionais de saúde dos sinais e sintomas clínicos das Síndromes Hipertensivas ${ }^{18}$.

Em estudo realizado uma maternidade pública no Estado do Piauí, no ano de 2013, a identificação de riscos e marcadores biológicos, precocemente, é fundamental para a prevenção ou redução dos riscos de mortalidade materna e fetal. Esta prevenção é possível na consulta pré-natal, entretanto os profissionais que realizam o pré-natal precisam estar sensíveis a esta situação, e também ter preparo técnico para realizar triagem satisfatória das gestantes de alto risco ${ }^{4}$.

Diante disto, durante a atuação do enfermeiro na atenção a gestante de risco, é exigido conhecimentos teóricos e práticos devido às situações de alta complexidade envolvidas, uma vez que esses aspectos não podem ser desconsiderados pelos enfermeiro, o qual deve ter a preocupação em estar preparado para desempenhar suas atividades assistenciais com competência e qualidade. A partir dessa atenção voltada a gestante é necessário cautela durante a exposição da sintomatologia para diagnosticar as síndromes hipertensivas e identificar se há ou não a evolução para a Síndrome HELLP ${ }^{16}$.

Portanto, a equipe de saúde, da qual o enfermeiro é integrante, deve estar atenta a todos os acontecimentos e dúvidas da gestante, buscando amenizar seu sofrimento através da orientação e ajuda. É necessário que o profissional 
enfermeiro possua conhecimento e sensibilidade, os quais são imprescindíveis para identificar, compreender e acompanhar alterações nos processos fisiológicos, patológicos e emocionais que permeiam a gestação de alto risco ${ }^{17}$.

Nesse processo, é importante o trabalho do enfermeiro em conjunto com o médico, seja da Unidade de Estratégia Saúde da Família ou do pré-natal de alto risco, fazendo a identificação dos sinais e sintomas e prestando assistência imediata. Sabe-se que as complicações da hipertensão gestacional são passíveis de prevenção com a ampliação da cobertura pré-natal e a preparação do pessoal de assistência, incluindo atenção primária, diagnóstico precoce de pacientes de alto risco ${ }^{18}$.

Assim, a atenção básica à mulher no ciclo gravídico e puerperal compreende medidas de prevenção e promoção da saúde, além de detectar e tratar precocemente intercorrências que propiciem evolução desfavorável para a mãe e ou para o feto. Para ser efetivo, o serviço deve propiciar assistência eficaz às gestantes, sendo indispensável que toda equipe conheça as características dessa clientela por eles assistidas ${ }^{1}$.

\section{CONSIDERAÇÕES FINAIS}

Conclui-se que a defasagem de conhecimento acerca da síndrome por parte dos enfermeiros é bem maior do que as descritas na literatura; essa falha remete a um diagnóstico tardio para a gestante e o aumento da mortalidade materno-fetal/neonatal. Percebe-se ainda que, devido à falta de conhecimento, os profissionais de enfermagem que atuam na atenção básica visam somente o controle da pressão arterial e de outras síndromes hipertensivas, deixando de analisar fatores que podem desencadear a Síndrome HELLP.

Por ser um agravo que envolve as gestações de alto risco, a síndrome HELLP carece de maior atenção, com um atendimento especializado por parte de profissionais capacitados e que realizem um acompanhamento preventivo eficaz. Sendo uma das principais causas de morte materna-fetal/neonatal, o enfermeiro deve adotar um acompanhamento prénatal de qualidade, principalmente para as gestantes com risco, como aquelas que evoluem com síndrome hipertensivas, fornecendo todas as ferramentas necessárias para que elas possam ter uma gravidez saudável e sem intercorrências.

O trabalho do enfermeiro com gestantes que possuem predisposição à síndrome HELLP requer atenção especial, conhecimento, responsabilidade, respeito e ética, tornando-se de extrema relevância escutar as pacientes de maneira individualizada, a fim de atender suas queixas e demandas, no intuito colaborar para a promoção e prevenção da saúde. Tendo em vista a tendência de aumento do número de casos desta patologia, cabe aos gestores propor atividades de educação em saúde com os profissionais envolvidos no intuito de aprimorar o conhecimento, para que possam atuar conforme as necessidades das gestantes. Tais ações tornam possível a realização do diagnóstico precoce, o que permite o levantamento de problemas, facilita a tomada de decisões e reflete a busca pela melhoria na assistência prestada. 
Diante do exposto, foi apontada, como limitação para o estudo, poucos artigos que retratasse o tema, e, portanto, subsidiassem a discussão. Entretanto, ressalta-se a relevância deste trabalho que evidenciou a necessidade em realizar pesquisas tangentes ao conhecimento do enfermeiro da atenção básica; além de revelar falhas no cuidado que tais profissionais prestam à gestante com Síndrome HELLP. Por fim, ressalta-se a importância da discussão acerca da $\mathrm{SH}$, para que o profissional de saúde, em especial o enfermeiro, possa desempenhar o papel assistencial com maior segurança, garantindo uma estabilidade e qualidade na assistência às gestantes.

\section{REFERÊNCIAS}

1. Rolim KMC, Costa RD, Thé RF, Abreu FRH. Agravos a saúde do recém-nascido relacionados à doença hipertensiva da gravidez: Conhecimento da Enfermeira. Rev Enferm Atenção Saúde [Internet]. 2014 [cited 2019 Jul 10];3(2):19-28. Available from: http://seer.uftm.edu.br/revistaeletronica/index.php/enfer/article/view/1017/880

2. Cunha HHS. Proteinúria e ácido úrico sérico maternos em pacientes com síndrome de HELLP.93f. Dissertação (Mestrado de Medicina e Ciências da Saúde) - Faculdade de Medicina da Pontíficia Universidade Católica do Rio Grande do Sul, Porto Alegre., 2012. Available from: http://tede2.pucrs.br/tede2/bitstream/tede/1708/1/443764.pdf

3. Lopes GT, Oliveira MCR, Silva KM, Silva IF, Ribeiro APLP. Hipertensão gestacional e a síndrome de HELLP: Ênfase nos cuidados de enfermagem. Rev Augustos [Internet]. 2013 [cited 2019 Jul 10];18(36):77-89. Available from: http://apl.unisuam.edu.br/revistas/index.php/revistaaugustus/article/view/1981-1896.2013v18n36p77/425

4. Nery IS, Viana LS, Viana LML, Araújo TME, Feitosa VC, Pereira VF. Perfil epidemiológico e obstétrico de gestantes com síndrome de HELLP. Cogitare Enferm [Internet]. 2014 [cited 2019 Jul 10];19(1): 147-52. DOI: http://dx.doi. org/10.5380/ce.v19i1.35973

5. Mao M, Chen C. Corticosteroid Therapy for Management of Hemolysis, Elevated Liver Enzymes, and Low Platelet Count (HELLP) Syndrome. Med Sci Monit [Internet]. 2015 [cited 2019 Jul 10];21:3777-83. DOI: 10.12659/ MSM.895220 
6. Oliveira RS, Matos IC, Silva TBP, Azevedo NM, Andradem, Espirito Santo FH. Síndrome de HELLP: Estudo de revisão para o cuidado de enfermagem. Rev Enferm Global [Internet]. 2012 [cited 2019 Jul 10];28:346-54. Available from: http://scielo.isciii.es/pdf/eg/v11n28/pt_revision2.pdf

7. Sampaio TAF, Santana TD, Hanzelmann RS, Santos LFM, Montenegro HRA, Martins JSA, et al. Cuidados de enfermagem prestados a mulheres com hipertensão gestacional e pré-eclâmpsia. Rev Saúde Física e Mental [Internet]. 2013 [cited 2019 Jul 10];2(1):36-45. Available from: http://revista.uniabeu.edu.br/index.php/SFM/article/ view/791/830

8. Lima JPC, Antunes MTP, Mendonça Neto OR, Peleias IR. Estudos de caso e sua aplicação: proposta de um esquema teórico para pesquisas no campo da contabilidade. Rev Contab Organizações [Internet]. 2012 [cited 2019 Jul 10];6(14):127-44. Available from: http://www.redalyc.org/articulo.oa?id=235223852007

9. Goldenberg MA. arte de pesquisar. Rio de Janeiro: Record, 1997.

10. Minayo MCS. Pesquisa social: teoria, método e criatividade. Petrópolis: Vozes, 2001.

11. Gaskell G. Entrevistas individuais e grupais. In: Bauer MW, Gaskell G. (Org). Pesquisa qualitativa com texto, imagem e som: um manual prático. Trad. Pedrinho A. Guareshi. Petropólis, RJ: Vozes, 2002.

12. Bauer MW. Análise de conteúdo clássica: uma revisão. In: Bauer MW, Gaskell G. (Org). Pesquisa qualitativa com texto, imagem e som: um manual prático. Petrópolis: Vozes, 2002. p. 189-217.

13. Aguiar LRS, Silva MGP, Feitosa WF, Cunha K. Análise de estudos sobre as condutas de enfermagem no cuidado a gestante com doença hipertensiva. Rev Interd [Internet]. 2014 [cited 2019 Jul 10];7(1):204-15. Available from: https://revistainterdisciplinar.uninovafapi.edu.br/index.php/revinter/article/view/252

14. Álvarez CEG, García LGG, García LC, Zabala MD, Rodríguez MS, Llorente RPA, et al. Hijo de madre con síndrome de HELLP: características y papel de la prematuridad, bajo peso y leucopenia en su evolución. Bol Med Hosp Infant Mex [Internet]. 2015 [cited 2019 Jul 10];72(5):318-24. DOI: http://dx.doi.org/10.1016/j.bmhimx.2015.09.006 
15. Brito KKG, Moura JRP, Sousa MJ, Brito JV, Oliveira SHS, Soares MJGO. Prevalência das síndromes hipertensivas específicas da gestação (SHEG). J Res Fundam Care online [Internet]. 2015 [cited 2019 Jul 10];7(3):271725. DOI: http://dx.doi.org/10.9789/2175-5361.2015.v7i3.2717-2725

16. Alexandre ACDO O conhecimento dos enfermeiros das unidades básicas de saúde da família do município de Esperança-PB acerca das síndromes hipertensivas da gravidez. Trabalho de Conclusão de Curso (Graduação em Enfermagem) - Centro de Ciências Biologicas e da Saúde. Campina Grande - PB, 2011. Available from: http://dspace.bc.uepb.edu.br/jspui/bitstream/123456789/759/1/PDF\%20-\%20Ana\%20Clara\%20de\%200liveira\%20Alexandre.pdf

17. Nour GFA, Castro MM, Fontenele FMC, Oliveira MS, Brito JO, Oliveira ARS. Mulheres com Síndrome Hipertensiva Específica da Gravidez: Evidências para o cuidado de enfermagem. SANARE [Internet]. 2015 [cited 2019 Jul 10];14(1):121-28. Available from: https://sanare.emnuvens.com.br/sanare/article/view/620/338

18. Gonçalves R, Fernandes RAQ, Sobral DH. Prevalência da doença hipertensiva específica da gestação em hospital público de São Paulo. Rev Bras Enferm [Internet]. 2005 [cited 2019 Jul 10];58(1):61-64. DOI: https://doi. org/10.1590/S0034-71672005000100011.

19. Ruiz MT, Azevedo CT, Ferreira MBG, Mamede MV. Associação entre síndromes hipertensivas e hemorragia pós-parto. Rev Gaúcha Enferm [Internet]. 2015 [cited 2019 Jul 10];36(esp):55-61. DOI: https://doi.org/10.1590/19831447.2015.esp.56776.

20. Abildgaard U, Heimdal K. Pathogenesis of the syndrome of hemolysis, elevated liver enzymes, and low platelet count (HELLP): a review. Eur J Obstet Gynecol Reprod Biol [Internet]. 2013 [cited 2019 Jul 10];166 (2):117-23. DOI: https://doi.org/10.1016/j.ejogrb.2012.09.026

21. Garrido MF, Carvajal JA. Síndrome de HELLP normotensivo: caso clínico. Rev méd Chile [Internet]. 2013 [cited 2019 Jul 10];141(11):1470-74. DOI: http://dx.doi.org/10.4067/S0034-98872013001100015.

22. Fiz YJ, Carrasco JOR, Estela OGC, Tan CEA. Síndrome de HELLP en una unidad de cuidados intensivos polivalente. Rev Arch Med Camagüey [Internet]. 2014 [cited 2019 Jul 10];18(5):475-85. Available from: http://scielo. sld.cu/pdf/amc/v18n5/amc040514.pdf 
23. Zuccolotto EB, Neto EP, Nogueira GC, Nociti JR. Anestesia para gestante com síndrome HELLP: relato de caso. Braz Jour Anesthesiol [Internet]. 2016 [cited 2019 Jul 10];66(6):657-60. DOI: http://dx.doi.org/10.1016/j. bjan.2014.05.013

24. Labarca L, Urdeta JR, González JE, Benítez AC, Baabel NS, Correa MF, et al. Prevalencia del síndrome de HELLP en gestantes críticas: Maternidad" Dr. Armando Castillo Plaza", Maracaibo, Venezuela. Rev Chil Obstet Ginecol [Internet]. 2016 [cited 2019 Jul 10];81(3):194-201. DOI: http://dx.doi.org/10.4067/S0717-75262016000300005

25. Sepulveda-Martinez A, Romero C, Juarez G, Hasbun J, Parra-Cordero M. Actualización en el diagnóstico y manejo del daño hepático agudo grave en el embarazo. Rev méd Chile [Internet]. 2015 [cited 2019 Jul 10];143(5):62736. DOI: http://dx.doi.org/10.4067/S003498872015000500011. 